\title{
KIR2DL2 combined with HLA-C1 confers risk of hepatitis C virus- related hepatocellular carcinoma in younger patients
}

\author{
Hiromi Saito ${ }^{1, *}$, Takeji Umemura ${ }^{1,2, *}$, Satoru Joshita ${ }^{1,2}$, Tomoo Yamazaki ${ }^{1}$, Naoyuki \\ Fujimori $^{1}$, Takefumi Kimura ${ }^{1}$, Michiharu Komatsu ${ }^{1}$, Akihiro Matsumoto ${ }^{1}$, Eiji \\ Tanaka $^{1}$ and Masao Ota ${ }^{1}$ \\ ${ }^{1}$ Department of Medicine, Division of Hepatology and Gastroenterology, Shinshu University School of Medicine, Matsumoto, \\ Japan \\ ${ }^{2}$ Research Center for Next Generation Medicine, Shinshu University, Matsumoto, Japan \\ *These authors have contributed equally to this work \\ Correspondence to: Takeji Umemura, email: tumemura@shinshu-u.ac.jp \\ Keywords: killer cell immunoglobulin-like receptor; human leukocyte antigen; hepatitis C virus; hepatocellular carcinoma; MICA \\ Received: December 26, $2017 \quad$ Accepted: March 06, $2018 \quad$ Published: April 13, 2018 \\ Copyright: Saito et al. This is an open-access article distributed under the terms of the Creative Commons Attribution License 3.0 \\ (CC BY 3.0), which permits unrestricted use, distribution, and reproduction in any medium, provided the original author and source \\ are credited.
}

\section{ABSTRACT}

Killer cell immunoglobulin-like receptors (KIRs) are involved in the activation and inhibition of natural killer cells. Although combinations of KIRs and HLA have been associated with spontaneous and treatment-induced clearance of hepatitis $C$ virus (HCV) infection, their roles are not fully understood in the context of hepatocellular carcinoma (HCC) development. We enrolled 787 consecutive patients with chronic HCV infection, which included 174 cases of HCC, and 325 healthy subjects to clarify the involvement of HLA-BW and C, KIRs, and major histocompatibility complex class I chain-related gene A (MICA) gene polymorphisms (rs2596542 and rs1051792) in chronic HCV infection and HCV-related HCC. We observed a significant association with chronic hepatitis C susceptibility for HLA-Bw4 $(P=0.00012$; odds ratio $[O R]=1.66)$ and significant protective associations for HLA-C2 and KIR2DL1-HLA-C2 (both $P=$ $0.00099 ;$ OR $=0.57$ ). When HCC patients were stratified into younger ( $<65$ years) and older ( $\geq 65$ years) groups, the frequencies of KIR2DL2-HLA-C1 and KIR2DS2-HLA-C1 $(P=0.008 ;$ OR $=2.89$ and $P=0.015 ; O R=2.79$, respectively $)$ as well as rs2596542 and rs1051792 $(P=0.020 ; O R=2.17$ and $P=0.038 ; O R=2.01$, respectively $)$ were significantly higher in younger patients. KIR2DL2-HLA-C1 $(O R=2.75 ; 95 \%$ confidence interval: 1.21-6.21, $P=0.015)$ and rs1051792 ( $O R=2.48 ; 95 \%$ confidence interval: $1.23-4.98, P=0.011$ ) were independently associated with $\mathrm{HCC}$ development in younger patients. These results suggest that KIR2DL2-HLA-C1 and rs1051792 may represent molecular biomarkers to identify early onset HCV-related HCC.

\section{INTRODUCTION}

Hepatitis $\mathrm{C}$ virus (HCV) infection is a major cause of chronic liver disease, with over half of patients with acute $\mathrm{HCV}$ infection developing chronic hepatitis and eventually liver cirrhosis and/or hepatocellular carcinoma (HCC) [1]. In Japan, HCC is one of the primary causes of cancer-related death, among which HCV-related HCC accounts for $60-70 \%$ of $\mathrm{HCC}$ cases nationwide [2]. The mechanisms involved in the progression of $\mathrm{HCV}$ infection to $\mathrm{HCC}$ have been related to viral, environmental, and host factors [3].

Natural killer (NK) cells respond to tumor cells and virally infected cells and kill them through the release of cytolytic granules or various chemokines and proinflammatory cytokines [4]. NK cells express multiple activation and inhibitory receptors to recognize changes in target cell state, and NK cell activity is controlled by a 
Table 1: Demographic and clinical characteristics of patients

\begin{tabular}{lcccc}
\hline Characteristic & Total $(\mathbf{n}=\mathbf{7 8 7})$ & Patients with HCC $(\mathbf{n}=\mathbf{1 7 4})$ & Patients without HCC $(\mathbf{n}=\mathbf{6 1 3})$ & $\boldsymbol{P}$ value \\
\hline Age, y & $68(43-82)$ & $70(52-82)$ & $67(41-82)$ & 0.011 \\
Male, n (\%) & $365(46.4)$ & $104(59.8)$ & $261(42.6)$ & $<0.001$ \\
Albumin, g/dL & $4.2(3.4-4.7)$ & $3.8(3.0-4.5)$ & $4.3(3.6-4.8)$ & $<0.001$ \\
Bilirubin, mg/dL & $0.8(0.4-1.6)$ & $0.9(0.5-1.8)$ & $0.8(0.4-1.5)$ & 0.006 \\
ALT, IU/L & $44(17-178)$ & $56(19-194)$ & $39(16-173)$ & $<0.001$ \\
Platelet count, $\times 10^{9} / \mathrm{L}$ & $15.8(6.7-25.6)$ & $10.6(4.9-21.6)$ & $16.8(9.1-26.9)$ & $<0.001$ \\
PT\% & $93.7(69.4-116.3)$ & $84.6(59.3-110.5)$ & $97.8(74.6-118.1)$ & $<0.001$ \\
AFP, ng/mL & $4.4(1.5-110.6)$ & $17.7(2.3-465.1)$ & $3.6(1.4-32.8)$ & $<0.001$ \\
HCV RNA, log IU/mL & $6.5(4.2-7.4)$ & $6.5(3.4-7.4)$ & $6.5(4.3-7.4)$ & 0.219 \\
HCV genotype 1, n $(\%)$ & $622(79.0)$ & $144(82.8)$ & $478(78.0)$ & 0.194 \\
\hline
\end{tabular}

Parameters are presented as the median $\left(5^{\text {th }}-95^{\text {th }}\right.$ percentiles $)$ for continuous variables and total number $(\%)$ for categorical variables. Abbreviations: HCC, hepatocellular carcinoma; ALT, alanine aminotransferase; PT, prothrombin time; AFP, $\alpha$ fetoprotein; HCV, hepatitis C virus.

delicate balance of stimulation and inhibitory signals [5]. The recognition of target cells by NK cells is determined by the integration of receptor signaling. Activation receptors on NK cells mainly recognize pathogen-derived, stress-induced, and tumor-specific ligands [6], while most inhibitory receptors interact specifically with human leukocyte antigen (HLA) class I molecules in humans [7]. The common ligands of NK cell receptors are HLA class I molecules (HLA-A,-B,-C,-E, and -G) and major histocompatibility complex (MHC) class I-like molecules (MHC class I chain-related molecules A and B; MICA and $\mathrm{MICB}$ ) [8]. NK cell surface receptors include the killer cell immunoglobulin-like receptor (KIR) family, which bind HLA-A,-B,-C, or -G, in addition to lectinlike molecules, inhibitory CD94-NKG2A, and activating CD94-NKG2C, which interact with HLA-E. Another NK cell-activating lectin-like receptor, NKG2D, recognizes multiple stress-inducible molecules, MICA, MICB, and the cytomegalovirus UL16-binding protein [9]. Thus, immunosurveillance for malignant cells is mainly mediated by the recognition of HLA class I molecules by KIRs and such NK cell-activating lectin-like receptors as NKG2D. In line with this model, the downregulation of MHC class I molecules on target cells promotes the activation of NK cells and their cytotoxic activity. CD94/ NKG2 heterodimers and KIRs are expressed by most NK cells and a minority of T cells. The inhibitory KIR2DL1 recognizes HLA-C group 2 (HLA-C2) allotypes that share lysine at position 80, while KIR2DL2 and KIR2DL3 are specific for HLA-C group 1 (HLA-C1) allotypes having asparagine at position 80 with different affinity [10]. KIR2DL2 and KIR2DL3 also recognize HLA-B*46:01 acquiring the $\mathrm{C} 1$ epitope by gene conversion [11]. Furthermore, KIR3DL1 binds with high affinity to HLA-
Bw4 molecules containing isoleucine at position 80 (Bw4[80I]) as compared with threonine (Bw4[80T]) [12].

NK cells have been implicated in the pathogenesis of $\mathrm{HCV}$ infection and HCC [13], specifically in the destruction of $\mathrm{HCV}$-infected cells. The loss of NK cell activity is correlated with the progression of $\mathrm{HCV}$ infection to HCC [14]. Receptor-ligand combinations of KIR and HLA have been associated with the natural clearance of $\mathrm{HCV}$ infection and anti-viral therapy outcome in patients with chronic hepatitis C [15-19]. Although several studies have described the relationship between KIR-HLA and HCV-related HCC [20, 21], the exact impact and role of KIR-HLA remains unknown in the Japanese population. Moreover, a recent genomewide association study revealed that single nucleotide polymorphisms (SNPs) in the MICA gene imparted susceptibility to HCV-related HCC in Japan [22].

The present study sought to clarify the relationships of HLA, KIR, KIR-HLA, and MICA SNPs with chronic $\mathrm{HCV}$ infection and the development of $\mathrm{HCC}$ in the Japanese population.

\section{RESULTS}

\section{Patient characteristics}

The demographic, virological, and clinical characteristics of our cohort are summarized in Table 1. Among the 787 patients, 174 (22.1\%) were diagnosed as having HCC. These patients had a significantly higher male ratio compared with controls. Age, bilirubin, ALT, and AFP were significantly higher and albumin, platelet count, and PT\% were significantly lower in patients with $\mathrm{HCC}$ than in those without. 
HLA and KIR genotyping in patients with chronic HCV infection and controls

Among HLA-Bw and -C alleles, the frequency of HLA-Bw4Bw6 in patients with chronic HCV infection was significantly higher than that in healthy subjects (44.5\% versus $35.4 \% ; P=0.0052 ; \mathrm{OR}=1.46$ ) (Figure
1A) (Table 2). Conversely, the HLA-Bw6 homozygote had a significantly lower frequency in $\mathrm{HCV}$-infected patients $(44.0 \%$ versus $56.6 \% ; P=0.00012$; $\mathrm{OR}=0.60)$. The frequency of HLA-Bw4 was significantly higher in patients with chronic hepatitis $\mathrm{C}$ than in controls $(56.0 \%$ versus $43.4 \% ; P=0.00012$; $\mathrm{OR}=1.66)$, as were those of HLA-Bw4(80I) (38.8\% versus $32.0 \% ; P=0.034$;

A

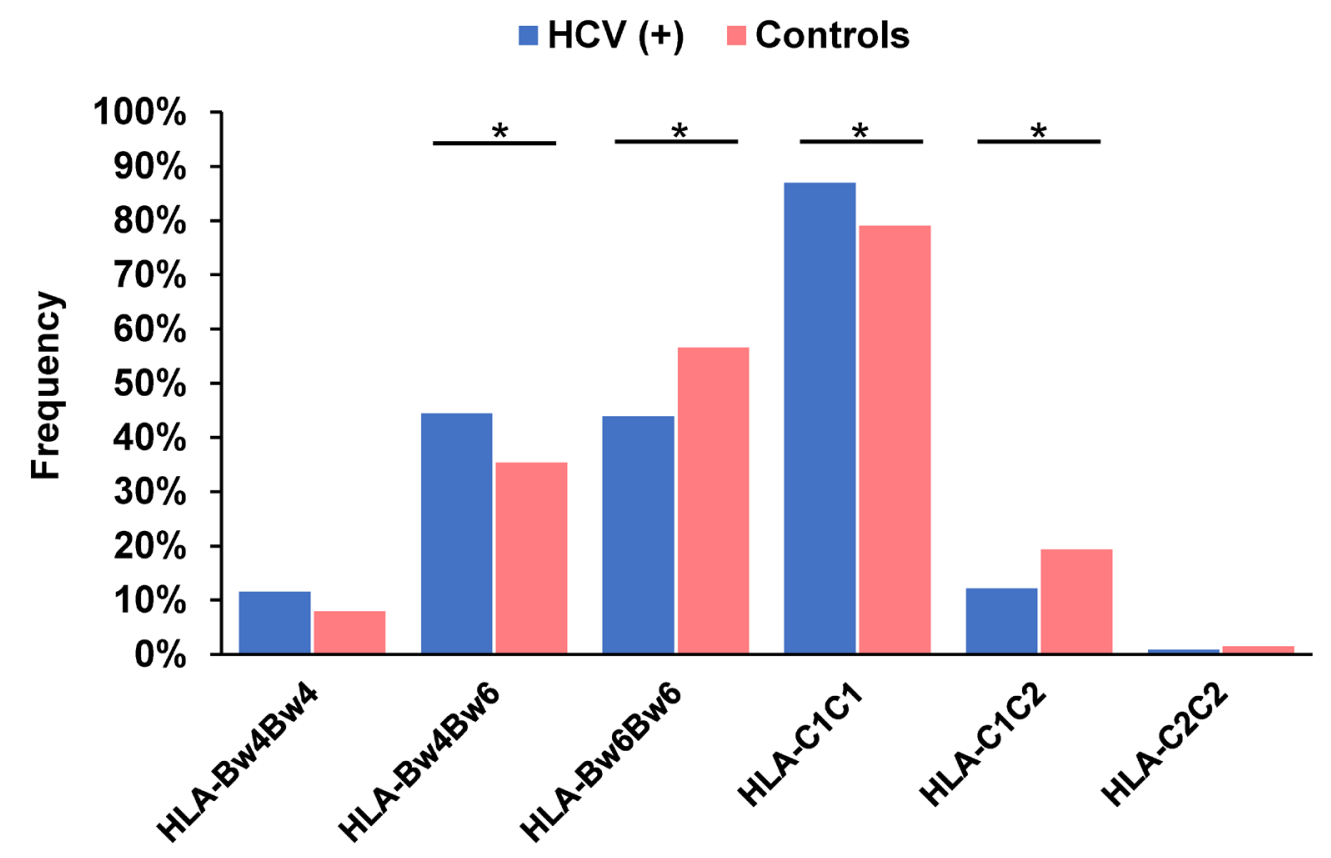

B

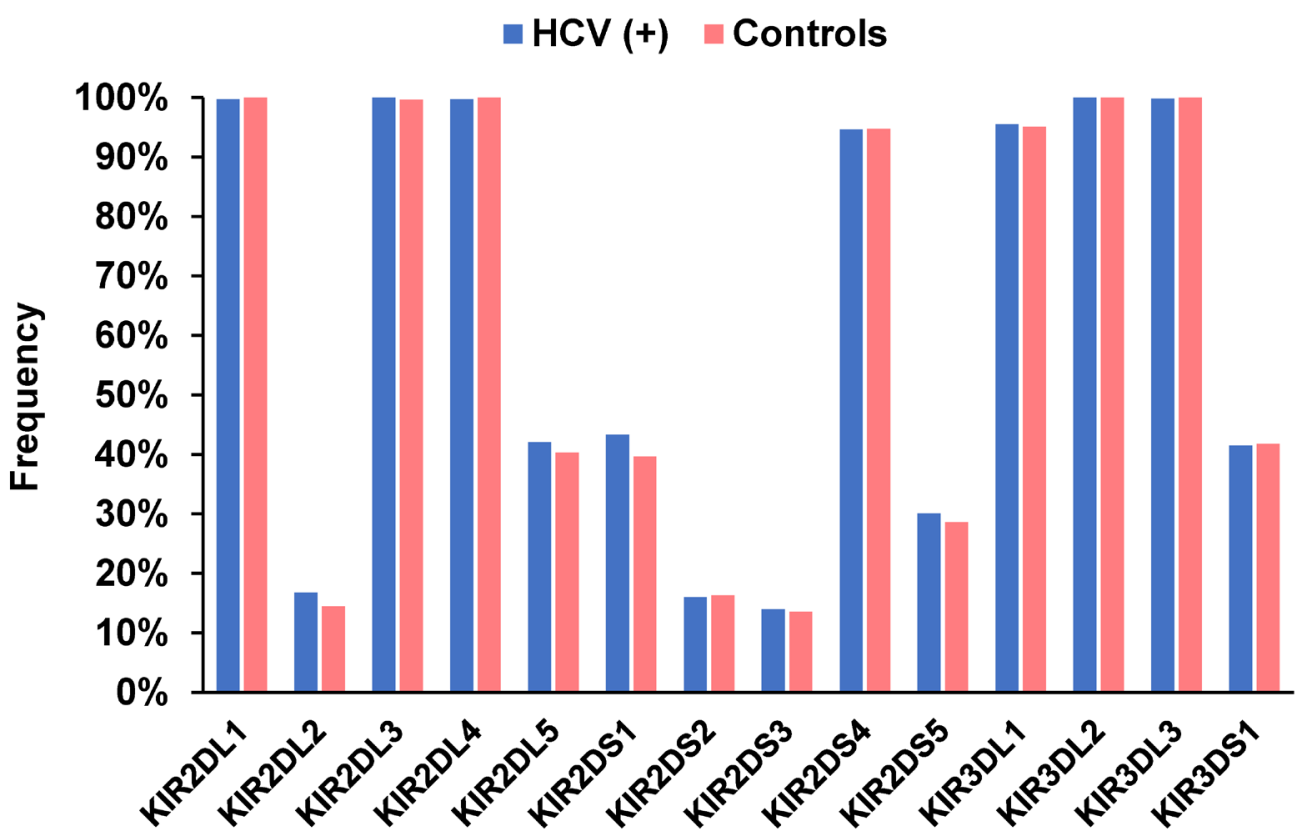

Figure 1: Frequency of HLA-Bw and -C (A) and each killer cell immunoglobulin-like receptor gene (B) in 787 patients with chronic hepatitis $\mathrm{C}$ and 325 healthy subjects. ${ }^{*} P<0.05$. 
Table 2: Frequency of HLA, KIR genes, and KIR-HLA combinations in patients with chronic hepatitis c and healthy controls

\begin{tabular}{lccccc}
\hline Genetic factor & HCV-positive $\mathbf{n}=\mathbf{7 8 7}$ & Controls $\mathbf{n}=\mathbf{3 2 5}$ & OR & $\mathbf{9 5 \%}$ CI & $\boldsymbol{P}$ value \\
\hline HLA-Bw4 & $441(56.0)$ & $141(43.3)$ & 1.66 & $1.28-2.16$ & 0.00012 \\
HLA-Bw4(80I) & $305(38.8)$ & $104(32.0)$ & 1.34 & $1.02-1.77$ & 0.034 \\
HLA-Bw4(80T) & $168(21.3)$ & $43(13.2)$ & 1.78 & $1.24-2.56$ & 0.0017 \\
HLA-Bw4Bw4 & $91(11.6)$ & $26(8.0)$ & 1.50 & $0.95-2.37$ & 0.078 \\
HLA-Bw4Bw6 & $350(44.5)$ & $115(35.4)$ & 1.46 & $1.12-1.91$ & 0.0052 \\
HLA-Bw6Bw6 & $346(44.0)$ & $184(56.6)$ & 0.60 & $0.46-0.78$ & 0.00012 \\
HLA-C1 & $780(99.1)$ & $320(98.5)$ & 1.74 & $0.55-5.53$ & 0.34 \\
HLA-C2 & $103(13.1)$ & $68(20.9)$ & 0.57 & $0.41-0.80$ & 0.00099 \\
HLA-C1C1 & $684(86.9)$ & $257(79.1)$ & 1.76 & $1.25-2.46$ & 0.00099 \\
HLA-C1C2 & $96(12.2)$ & $63(19.4)$ & 0.58 & $0.41-0.82$ & 0.0018 \\
HLA-C2C2 & $7(0.9)$ & $5(1.5)$ & 0.57 & $0.18-1.82$ & 0.34 \\
2DL1+HLA-C2 & $103(13.1)$ & $68(20.9)$ & 0.57 & $0.41-0.80$ & 0.00099 \\
2DS1+HLA-C2 & $40(5.1)$ & $26(8.0)$ & 0.62 & $0.37-1.03$ & 0.061 \\
3DL1+HLA-Bw4 & $425(54.0)$ & $135(41.5)$ & 1.65 & $1.27-2.15$ & 0.00016 \\
3DL1+HLA-Bw4(80I) & $296(37.6)$ & $99(30.5)$ & 1.38 & $1.04-1.82$ & 0.023 \\
3DL1+HLA-Bw4(80T) & $161(20.5)$ & $42(12.9)$ & 1.73 & $1.20-2.50$ & 0.0031 \\
\hline
\end{tabular}

Parameters are presented as total number (\%).

Abbreviations: HLA, human leukocyte antigen; KIR, killer cell immunoglobulin-like receptor; HCV, hepatitis C virus; OR, odd ratio; CI, confidence interval.

$\mathrm{OR}=1.34)$ and HLA-Bw4(80T) $(21.3 \%$ versus $13.2 \%$; $P=0.0017$; OR $=1.78)$. The presence of one copy of HLA-C1 (HLA-C1C2) was significantly associated with controls $(P=0.0018$; OR $=0.58)$, while that of two copies (HLA-C1C1) was found more frequently in patients with chronic hepatitis $\mathrm{C}(86.9 \%$ versus $79.1 \%$; $P=0.00099$; $\mathrm{OR}=1.76)$. Hence, higher HLA-C1 copy number was associated with more frequent chronic $\mathrm{HCV}$ infection. Lastly, HLA-C2 was significantly less frequent in patients with chronic $\mathrm{HCV}$ infection $(13.1 \%$ versus $20.9 \% ; P=$ 0.00099; OR = 0.57). With respect to KIR genes, there were no significant differences between $\mathrm{HCV}$-infected patients and healthy controls (Figure 1B).

We next analyzed combinations of activation/ inhibitory KIRs and their ligands for possible relationships with HCV infection. The frequency of the KIR2DL1HLA-C2 combination in patients with chronic hepatitis $\mathrm{C}$ was significantly lower than that in controls $(13.1 \%$ versus $20.9 \% ; P=0.00099 ; \mathrm{OR}=0.57)$. In contrast, $\mathrm{HCV}$ infected patients had a significantly higher frequency of KIR3DL1-HLA-Bw4 $(54.0 \%$ versus $41.5 \% ; P=$ 0.00016 ; OR $=1.65$ ). It was noteworthy that KIR3DL1HLA-Bw4(80I) and KIR3DL1-HLA-Bw4(80T) were significantly more common in $\mathrm{HCV}$-infected patients (37.6\% versus $30.5 \% ; P=0.023$; OR $=1.37$ and $20.5 \%$ versus $12.9 \%$; $P=0.0031$; OR $=1.73$, respectively).

\section{HLA and KIR genotyping in patients with or without $\mathrm{HCC}$}

To clarify the effect of HLA alleles and KIR genes on $\mathrm{HCC}$ development, their genotype frequencies were compared between $\mathrm{HCV}$-infected patients with and without HCC. No specific HLA alleles (Figure $2 \mathrm{~A}$ ) or KIR genes (Figure 2B) were detected, nor were there any significant relationships involving KIR-HLA combinations.

Next, we stratified patients with chronic hepatitis $\mathrm{C}$ into younger ( $<65$ years) and older ( $\geq 65$ years) groups to examine the clinical characteristics and associations of HLA and KIR genes with HCC development according to age (Figure 3A and 3B). Younger patients with HCC had a significantly higher male ratio, significantly higher ALT, and significantly lower PT\% (Table 3 ). The frequencies of the HLA-Bw4 and HLA-C1 alleles were comparable between the groups (Table 4). With respect to KIR genes, the frequencies of KIR2DL2 and KIR2DS2 were significantly higher in younger HCC patients $(28.8 \%$ versus $13.1 \% ; P=0.013 ; \mathrm{OR}=2.69$ and $25.0 \%$ versus $11.5 \% ; \mathrm{P}=0.024 ; \mathrm{OR}=2.57$, respectively) (Table 4). Conversely, younger patients had significantly lower frequencies of KIR2DS5 (13.5\% versus $32.0 \% ; P=$ $0.018 ; \mathrm{OR}=0.33)$ and KIR3DS1 $(25.0 \%$ versus $44.3 \% ; P$ 
A

$\square \mathrm{HCC}(+) \square \mathrm{HCC}(-)$

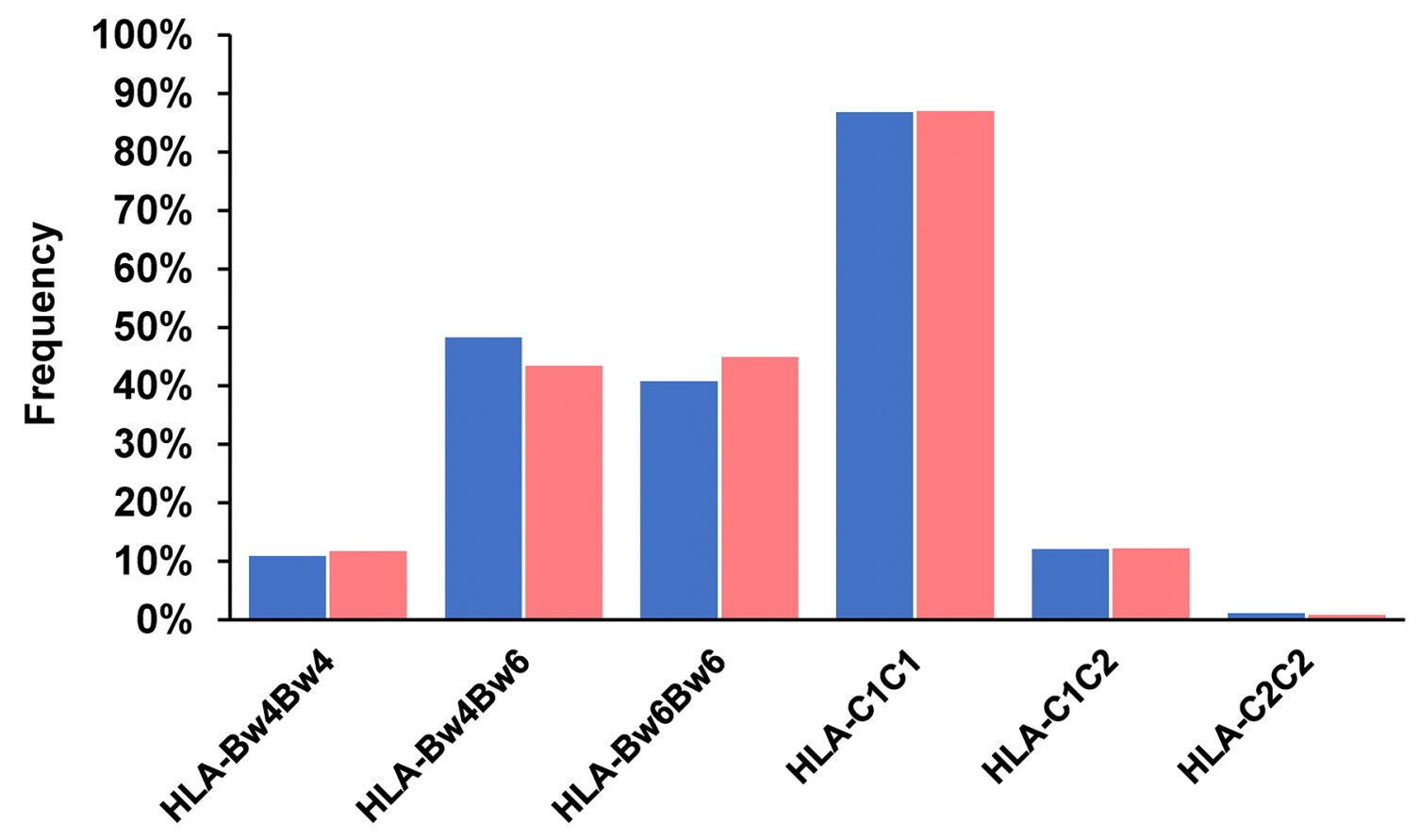

B

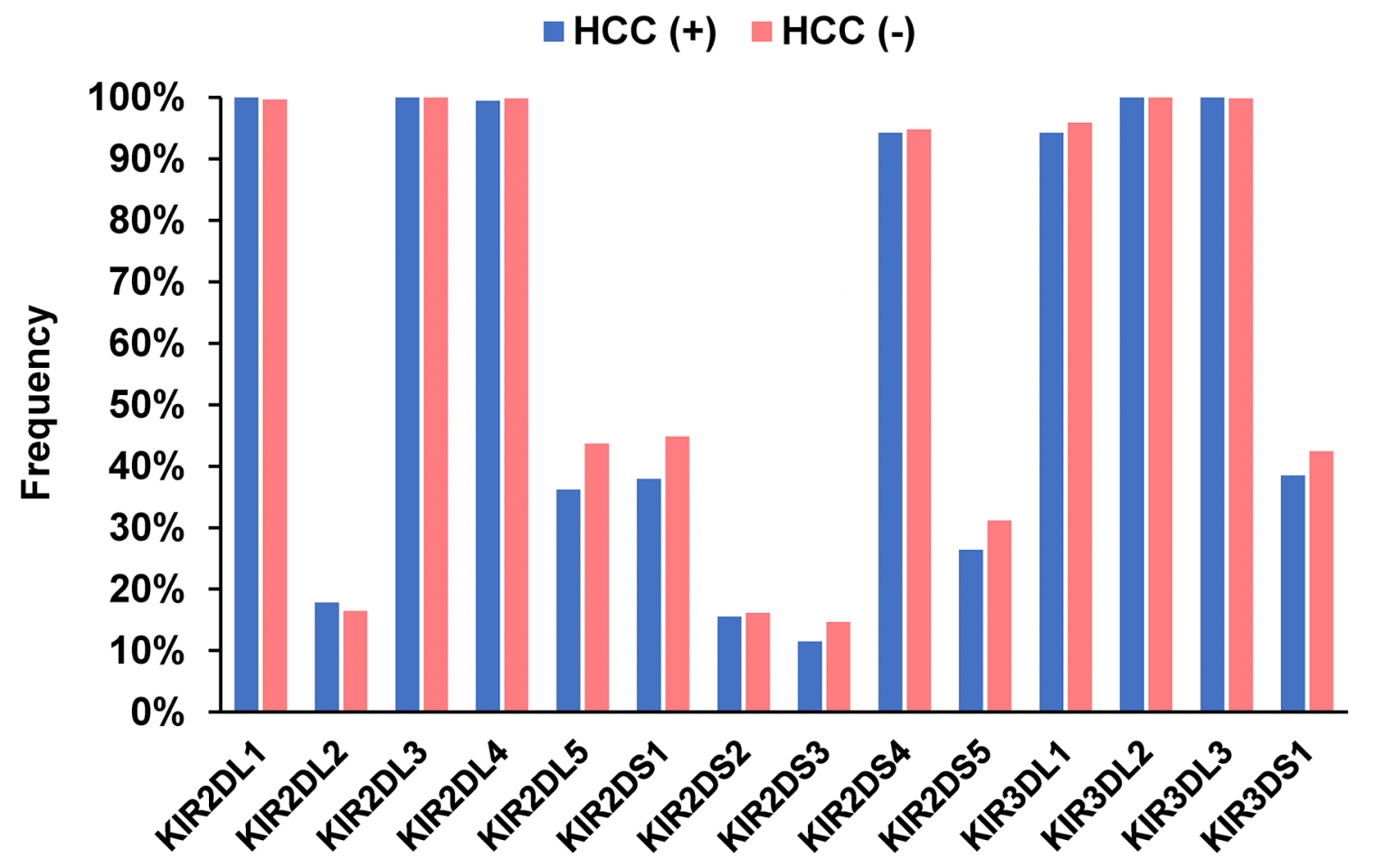

Figure 2: Frequency of HLA-Bw and -C (A) and each killer cell immunoglobulin-like receptor gene (B) in 174 patients with hepatocellular carcinoma and 613 patients without. 
A

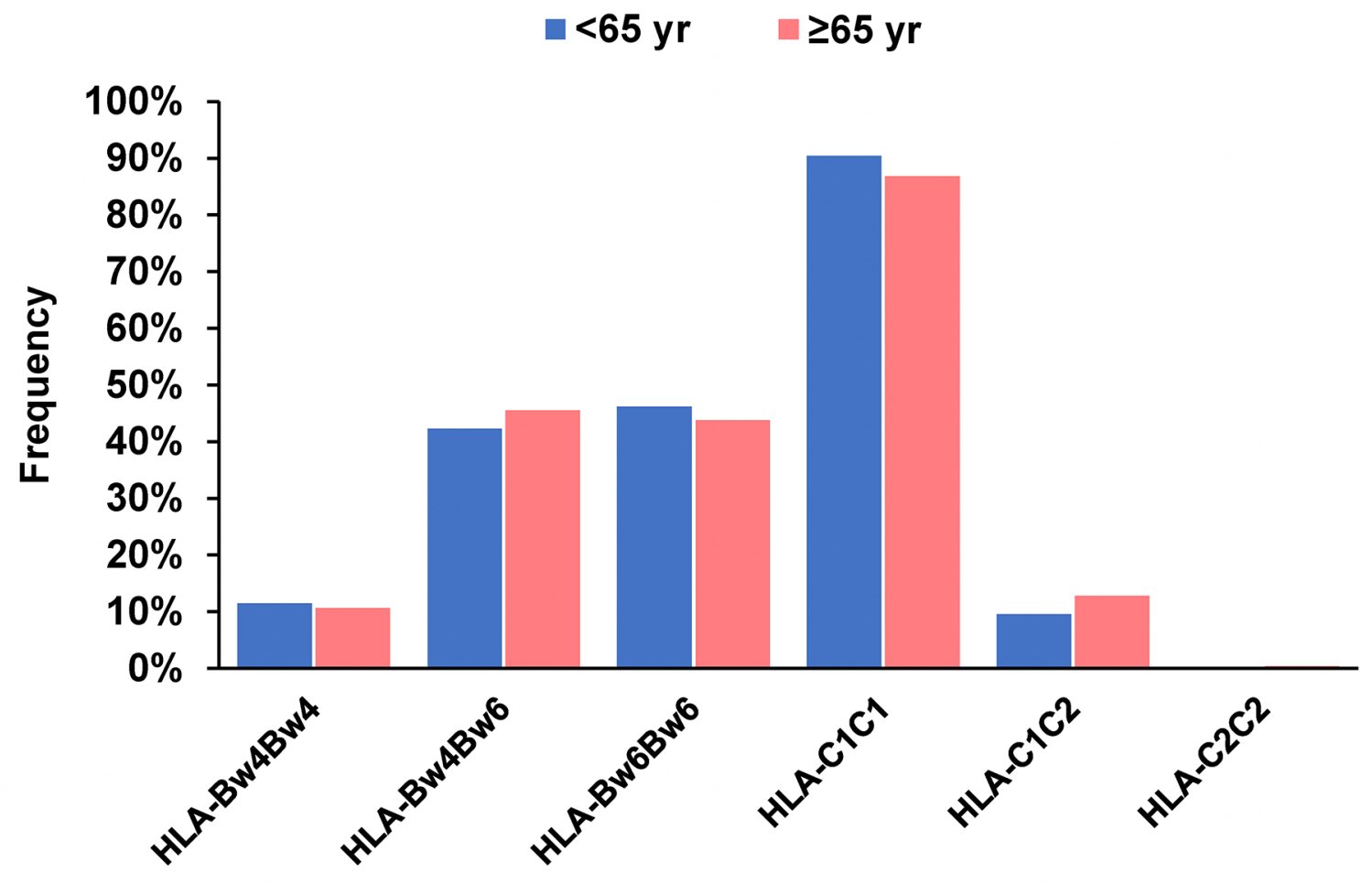

B

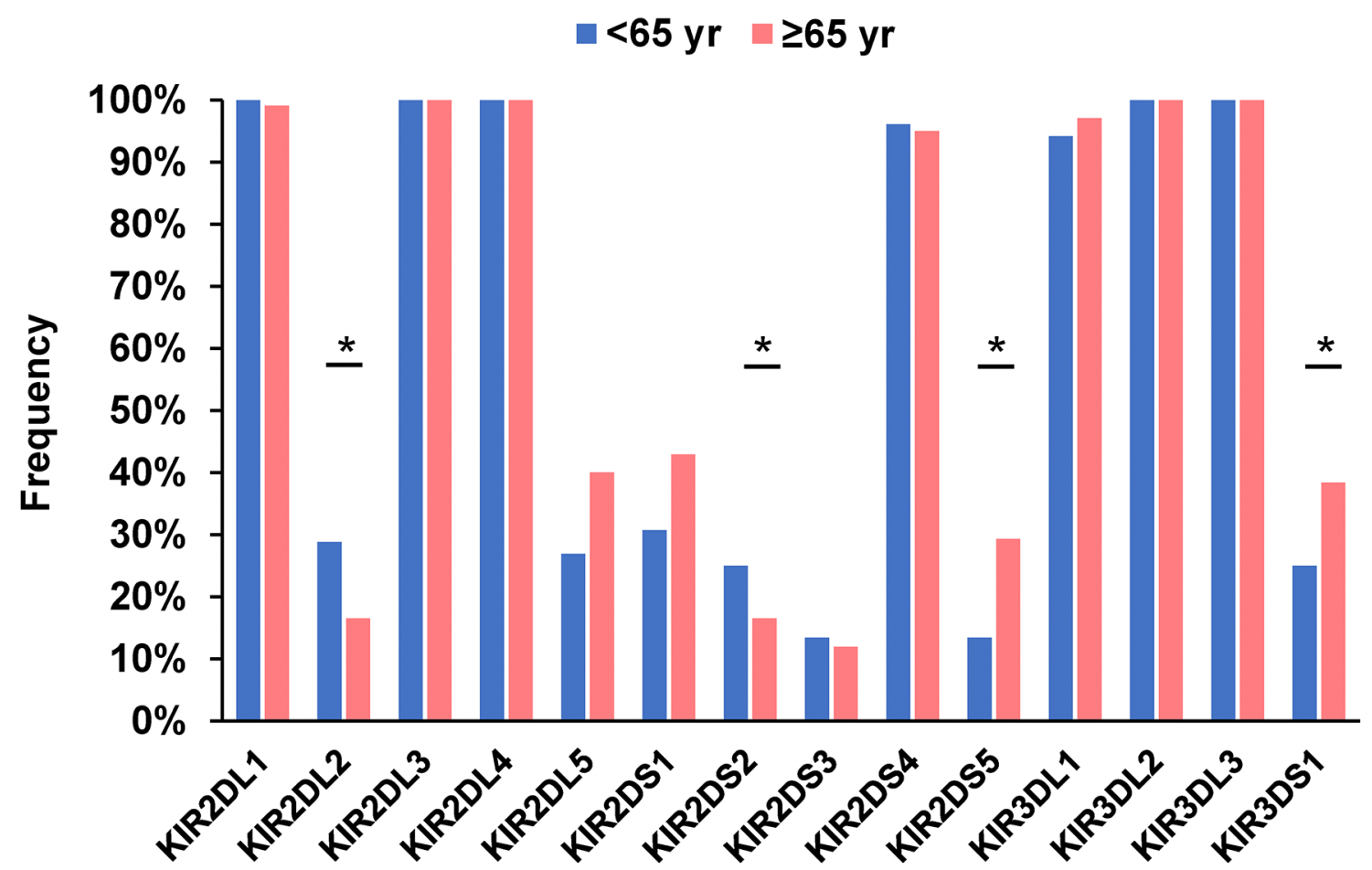

Figure 3: Frequency of HLA-Bw and -C (A) and each killer cell immunoglobulin-like receptor gene (B) in 52 younger $(<65$ years) patients and 122 older ( $\geq 65$ years) patients with hepatocellular carcinoma. ${ }^{*} P<0.05$. 
Table 3: Demographic and clinical characteristics of patients with HCC stratified by age

\begin{tabular}{lccc}
\hline Characteristic & $<\mathbf{6 5}$ years $(\mathbf{n}=\mathbf{5 2})$ & $\mathbf{2 6 5}$ years $(\mathbf{n}=\mathbf{1 2 2})$ & $\boldsymbol{P}$ value \\
\hline Age, y & $60(46-64)$ & $72(65-83)$ & $<0.001$ \\
Male, n (\%) & $37(71.2)$ & $67(54.9)$ & 0.046 \\
Albumin, g/dL & $3.8(3.1-4.5)$ & $3.8(2.8-4.5)$ & 0.909 \\
Bilirubin, mg/dL & $0.9(0.4-2.9)$ & $0.8(0.5-1.6)$ & 0.211 \\
ALT, IU/L & $62(23-264)$ & $10.9(5.3-20.8)$ & 0.028 \\
Platelet count, $\times 10 / \mathrm{L}$ & $10.1(3.6-25.6)$ & $86.3(61.9-109.9)$ & 0.317 \\
PT\% & $79.0(57.3-115.9)$ & $15.6(2.1-666.9)$ & 0.012 \\
AFP, ng/mL & $25.8(3.0-175.1)$ & $6.3(3.4-7.4)$ & 0.236 \\
HCV RNA, log IU/mL & $6.6(2.8-7.4)$ & $105(86.1)$ & 0.291 \\
HCV genotype $1, \mathrm{n}(\%)$ & $39(75.0)$ & 0.077 \\
\hline
\end{tabular}

Parameters are presented as the median $\left(5^{\text {th }}-95^{\text {th }}\right.$ percentiles $)$ for continuous variables and total number $(\%)$ for categorical variables.

Abbreviations: HCC, hepatocellular carcinoma; ALT, alanine aminotransferase; PT, prothrombin time; AFP, $\alpha$ fetoprotein; $\mathrm{HCV}$, hepatitis $\mathrm{C}$ virus.

$=0.017 ; \mathrm{OR}=0.42)$. We then evaluated the influence of KIR-HLA combinations on HCC development in younger patients and witnessed the combinations of KIR2DL2HLA-C1 and KIR2DS2-HLA-C1 to be significantly associated with younger HCC patients versus older patients $(28.8 \%$ versus $12.3 \% ; P=0.008$; OR $=2.89$ and $25.0 \%$ versus $10.7 \% ; P=0.015 ; \mathrm{OR}=2.79$, respectively). No other KIR or KIR-HLA combinations differed between the groups.

Since several studies have reported that KIRligand copy number may influence NK cell functionality, we searched for associations between KIR2DL2 or KIR2DS2-HLA-C1 copy number and HCC development in the younger group (Table 4). HCC patients were stratified by HLA-C1 copy number into those lacking an HLA-C1 allele (HLA-C2C2), those carrying one HLA-C1 allele (HLA-C1C2), and those carrying homozygote HLA-C1 alleles (HLA-C1C1) (Table 4). Patients expressing KIR2DL2-HLA-C1 motifs were significantly more frequent in the younger group $(28.8 \%)$ compared with the older group $(9.8 \% ; P=0.0015$; OR $=$ 3.72). Similarly, when KIR2DS2-HLA-C1 copy number was examined, the frequency of HCC patients with homozygote $\mathrm{C} 1$ alleles was also higher in the younger group $(25.0 \%$ versus $8.2 \% ; P=0.0027$; $\mathrm{OR}=3.73)$. Among chronic $\mathrm{HCV}$-infected patients without $\mathrm{HCC}$, no HLA alleles or KIR genes were significantly associated with younger or older groups.

\section{MICA SNP genotyping}

We evaluated two MICA SNPs for associations with chronic hepatitis C and HCV-related HCC in our cohort. The frequencies of the rs 2596542 A allele (39.1\% versus $34.2 \% ; P=0.027 ; \mathrm{OR}=1.24)$ and $\mathrm{rs} 1051792 \mathrm{~A}$ allele $(40.3 \%$ versus $34.3 \%$; $P=0.0078$; $\mathrm{OR}=1.29)$ in patients with chronic hepatitis $\mathrm{C}$ were significantly higher than those in controls, but no remarkable results were observed between patients with and without HCC. When HCC patients were stratified according to younger or older age, the frequencies of the minor A alleles at rs 2596542 and rs 1051792 were significantly higher in the younger HCC group $(44.2 \%$ versus $32.4 \% ; P=0.035$; OR $=$ 1.66 and $52.9 \%$ versus $37.7 \% ; P=0.0087$; OR $=1.85$, respectively). The frequency of the AA genotype of both SNPs also differed significantly between the age groups $(25.0 \%$ versus $10.7 \% ; P=0.015 ; \mathrm{OR}=2.79$ and $44.2 \%$ versus $24.6 \% ; P=0.010$; OR $=2.43$, respectively).

\section{Factors independently associated with $\mathrm{HCC}$ in younger individuals}

The results of logistic regression analysis regarding factors associated with $\mathrm{HCC}$ development in younger patients revealed KIR2DL2-HLAC1C1 (OR $=2.75$; 95\% CI: 1.21 $6.21, P=0.015)$ and $\mathrm{rs} 1051792 \mathrm{AA}(\mathrm{OR}=2.48 ; 95 \% \mathrm{CI}$ : $1.23-4.98, P=0.011$ ) to be significant risk factors for HCC.

\section{DISCUSSION}

This study examined HLA alleles and KIR genes in Japanese patients with chronic hepatitis $\mathrm{C}$ for associations with HCC development and revealed significant relationships for HLA-Bw and -C alleles as well as combinations of KIRHLA in chronic HCV infection. Moreover, a KIR-HLA and SNP in the MICA gene were significantly associated with earlier development of HCC at a cut-off age of 65 years. 
Table 4: Frequency of HLA, KIR genes and KIR-HLA combinations in patients with HCC stratified by age

\begin{tabular}{lccccc}
\hline Genetic factor & $<\mathbf{6 5}$ years $(\mathbf{n}=\mathbf{5 2})$ & $\mathbf{2 6 5}$ years $(\mathbf{n}=\mathbf{1 2 2})$ & $\mathbf{O R}$ & $\mathbf{9 5 \%} \mathbf{C I}$ & $\boldsymbol{P}$ value \\
\hline HLA-Bw4 & $28(53.8)$ & $75(61.5)$ & 0.73 & $0.38-1.41$ & 0.35 \\
HLA-C1 & $52(100.0)$ & $120(98.4)$ & - & - & 0.35 \\
2DL2 & $15(28.8)$ & $16(13.1)$ & 2.69 & $1.21-5.96$ & 0.013 \\
2DS2 & $13(25.0)$ & $14(11.5)$ & 2.57 & $1.11-5.95$ & 0.024 \\
2DS5 & $7(13.5)$ & $39(32.0)$ & 0.33 & $0.14-0.80$ & 0.011 \\
3DS1 & $13(25.0)$ & $54(44.3)$ & 0.42 & $0.20-0.86$ & 0.017 \\
2DL2+HLA-C1 & $15(28.8)$ & $15(12.3)$ & 2.89 & $1.29-6.48$ & 0.008 \\
2DL2+HLA-C1C1 & $15(28.8)$ & $12(9.8)$ & 3.72 & $1.60-8.66$ & 0.0015 \\
2DS2+HLA-C1 & $13(25.0)$ & $13(10.7)$ & 2.79 & $1.19-6.55$ & 0.015 \\
2DS2+HLA-C1C1 & $13(25.0)$ & $10(8.2)$ & 3.73 & $1.52-9.20$ & 0.0027 \\
\hline
\end{tabular}

Parameters are presented as total number (\%).

Abbreviations: HLA, human leukocyte antigen; KIR, killer cell immunoglobulin-like receptor; HCC, hepatocellular carcinoma; OR, odd ratio; CI, confidence interval.

Regarding the role of class I HLA-restricted T-cell immune responses in the control of HCV pathogenesis [23], several studies have uncovered associations between HCV infection and HLA class I alleles [19, 24]. Here, HLA-Bw4 was significantly more frequent in patients with chronic HCV infection than in healthy subjects. Conversely, subjects with chronic hepatitis $\mathrm{C}$ had a significantly lower frequency of HLA-C2. It has been well documented that certain combinations of KIR and KIR ligands are associated with susceptibility to HCV infection. This study revealed that patients with chronic hepatitis $\mathrm{C}$ had a significantly higher incidence rate of KIR3DL1-HLA-Bw4 pairs. It was described elsewhere that individuals carrying KIR3DL1-HLA-Bw4 were of higher NK cell functional potential than HLA-Bw4negative individuals since the KIR3DL1+ NK subset in HLA-Bw4-positive subjects was more potent $[25,26]$ and that KIR3DL1 receptors did not bind Bw6 allotypes [27], which was consistent with NK cell licensing [28, 29]. Thöns et al. [30] recently showed that KIR3DL1-HLA$\mathrm{Bw} 80(\mathrm{~T})$ was associated with spontaneous clearance of $\mathrm{HCV}$ infection in intravenous drug users.

Peripheral and intrahepatic NK cells in HCC patients were reported to display impairments in cytotoxicity and interferon- $\gamma$ production [31]. Wu et al. described that the accumulation of functional NK cells in HCC tissues could predict improved patient survival, while NK cells were decreased in number, with impaired tumor necrosis factor- $\alpha$ and interferon- $\gamma$ production, in patients with advanced-stage HCC [32]. HCV-induced HCC is a multistep, progressive liver disease likely influenced by both environmental and genetic factors. Given the functional mechanism and extensive genomic diversity of KIRs and their HLA ligands, several specific KIR-ligand combinations could accelerate disease progression. In fact, the combination of KIR3DS1 and HLA-Bw4 or -Bw4(I80) was under-represented in HCC patients as compared with HCV carriers without HCC from Spain and Italy [20, 21]. However, our data did not confirm these results or show associations among HLA alleles, KIR genes, or KIR-HLA pairs and HCV-related HCC.

The prevalence of older patients with $\mathrm{HCC}$ has been increasing in Japan [2]. which is also an impending problem in other countries with recent viral spread. Asahina et al. reported that elderly patients of $\geq 65$ years were at higher risk for HCV-related $\mathrm{HCC}$ and that aging was a risk factor for HCC [33]. This prompted us to analyze whether KIRHLA combinations influenced the development of HCVrelated $\mathrm{HCC}$ in this age group. Interestingly, we revealed associations between KIR2DL2-HLA-C1 and KIR2DS2HLA-C1 combinations and HCC in younger individuals. Aging is associated with changes in the frequency, phenotype, and function of NK cell subsets [34]. Lutz et al. revealed an age-related decrease in CD94 and NKG2A expression and a reciprocal age-dependent increase in KIR expression, although this has remained controversial [35]. Moreover, changes in NK cell phenotype in the elderly lead to alterations in cell function, with a decrease in cytotoxicity at the single-cell level and a reduced ability to respond and produce cytokines after stimulation. In the present study, HLA frequencies did not differ between younger and older patients without HCC. Therefore, specific KIR-HLA pairs are presumed to participate in immunosurveillance for HCC. The frequency of KIR2DL2-HLA-C1 was significantly higher in younger patients with HCC (28.8\% versus $16.5 \%$; $P=0.039$; OR $=2.05$ ) when KIR-HLA combinations were examined between younger patients with $\mathrm{HCC}$ and those without. There were no significant differences between 
older patients with and without HCC. To explain the higher frequency of KIR2DL2-HLA-C1 in younger HCC patients, we considered that NK-cell activation was inhibited by KIR2DL1-HLA-C1, thus rendering them unable to kill HCC cells. However, such a notion is highly speculative and requires additional studies to validate. At present, we can only describe a possible relationship of KIR2DL2HLA-C1 with HCC development in younger patients.

A recent genome-wide association study revealed that rs2596542 in the 5' flanking region of MICA was associated with HCV-related HCC and soluble form MICA levels in the Japanese population [22]. Furthermore, the serum soluble form of MICA was elevated in advanced HCC patients and associated with downregulated NKG2D expression and impaired NK cell activation [36]. The engagement of MICA and NKG2D strongly activates NK cells, enhancing both cytotoxic granule exocytosis and cytokine secretion. [37] NKG2D ligand (MICA or MICB) recognition by NKG2D induces and/or enhances immune responses to cancer cells [38]. Hence, the pathophysiological effects of MICA SNPs represent a prognostic biomarker for patients with chronic hepatitis C-induced HCC [39]. Although our findings did not support a relationship of SNPs in the MICA gene with $\mathrm{HCC}$, they did reveal associations with $\mathrm{HCC}$ in younger patients. The reasons for this discrepancy may be attributed to the smaller number of patients in the present study.

In logistic regression analysis of our cohort, KIR2DL2-HLA-C1C1 and rs1051792AA in the MICA gene were independent risk factors related to $\mathrm{HCC}$ in patients of less than 65 years, indicating at least two genetic factors that may offer clinicians additional insights into predicting HCC development in younger individuals. Kaplan-Meier analysis of HCC development in a non-HCC group over time would be an ideal method to clarify whether our identified genetic factors imparted susceptibility to HCC development. Since the present study is cross-sectional, further large-scale prospective investigations are needed to confirm our findings.

In conclusion, HLA alleles, KIR3DL1-HLA-Bw4, and KIR2DL1-HLA-C2 are associated with either HCV susceptibility or protection in the Japanese population. KIR2DL2-HLA-C1 and KIR2DS2-HLA-C1 are novel KIR-HLA pairs linked to the development of HCC in younger patients, as are SNPs in the MICA gene. Investigation of the frequency, phenotype, and function of NK cells in age-stratified patients with HCV-induced $\mathrm{HCC}$ will be necessary to identify the precise mechanism of susceptibility to HCC in Japan.

\section{MATERIALS AND METHODS}

\section{Study population}

A total of 787 consecutive patients with chronic hepatitis $\mathrm{C}$ were enrolled in this retrospective study from Shinshu University Hospital in Matsumoto, Japan, between
September 2003 and August 2015. We also recruited 325 volunteer control subjects from hospital staff who had indicated the absence of any major illness in a standard questionnaire. The racial background of all patients was Japanese. Eligible patients were at least 20 years of age and confirmed to have chronic hepatitis $\mathrm{C}$ based on the previously reported criteria of the presence of serum antiHCV antibodies and detectable HCV RNA [40]. All patients and controls were negative for the hepatitis B surface antigen and antibodies to the human immunodeficiency virus. Patients who exhibited other causes of chronic liver disease, such as alcoholic liver disease, non-alcoholic liver disease, primary biliary cholangitis, or autoimmune hepatitis, were excluded. Serum levels of HCV RNA were determined using the Cobas TaqMan HCV test (Roche Diagnostic Systems, Tokyo, Japan) with a linear dynamic range of 1.2-7.8 $\log \mathrm{IU} / \mathrm{mL}$. HCV genotypes were determined by sequence analysis. Total bilirubin, alanine aminotransferase, and other relevant biochemical tests were performed using standard methods. The diagnosis of HCC was based on hypervascularity confirmed by dynamic computed tomography and/or magnetic resonance imaging when serum alpha fetoprotein level was increased or a mass lesion was detected by ultrasonography. This study was conducted in accordance with the principles of the 2013 Declaration of Helsinki after review and approval by the ethics committee of Shinshu University School of Medicine in Matsumoto, Japan (No. 527). Informed consent was obtained from each patient included in the study.

\section{HLA class I, KIR, and MICA genotyping}

Genomic DNA from patients and controls was isolated from whole blood samples using QuickGene-800 assays (Fujifilm, Tokyo, Japan). HLA-Bw4, -C1, and -C2 genotyping [41] and KIR genotyping [42] were performed using PCR with sequence-specific primers. HLA typing was combined with KIR typing to stratify patients according to predicted KIR-ligand interactions and binding affinities. These KIR-HLA pairs were KIR2DL1/2DS1-HLA-C2, 2DL2/3/2DS2-HLA-C1, and 3DL1/3DS1-HLA-Bw4. Genotyping of rs2596542 and rs1051792 in the MICA gene was performed using the TaqMan SNP genotyping allelic discrimination method (Applied Biosystems, Foster City, CA). The rs2596542 has been associated with $\mathrm{HCV}$-induced $\mathrm{HCC}$ in a GWAS [22], and rs1051792 corresponds to a methionine/valine polymorphism at amino acid 129 of MICA, with the methionine allele as a strong binder to NKG2D [43]. Both SNPs had minor allele frequencies of $>5 \%$. All genotyping was blinded to clinical variables.

\section{Statistical analysis}

The Mann-Whitney U test was employed to analyze continuous variables. Pearson's chi-squared test or Fisher's exact test was used for the analysis of 
categorical data. A $P$ value of $<0.05$ was considered to be statistically significant. Association strength was estimated by calculating the odds ratio (OR) and 95\% confidence interval (CI). Stepwise logistic regression analysis with a forward approach was performed to identify independent factors associated with HCC that were separated into two categorical variables by their median value. Variables associated with a $P<0.05$ in univariate analysis were included in this step. Statistical analyses were carried out using SPSS Statistics 24 software (IBM, Tokyo, Japan).

\section{Abbreviations}

HCC, hepatocellular carcinoma; HCV, hepatitis C virus; HLA, human leukocyte antigen; KIR, killer cell immunoglobulin-like receptor; MHC, major histocompatibility complex; MIC, major histocompatibility complex class I chain-related gene; NK cell, natural killer cell; OR, odds ratio; SNP, single nucleotide polymorphism.

\section{Author contributions}

HS,TU and MO conceived and designed the study. HS performed experiments. TU, SJ, TY, NF, TK, MK, $\mathrm{AM}$, and ET recruited patients and collected samples. $\mathrm{HS}$, TU, and MO analyzed data. HS, TU and MO interpreted experimental results. TU, and $\mathrm{MO}$ drafted the manuscript. All authors have seen and approved the final manuscript.

\section{ACKNOWLEDGMENTS}

The authors thank Yuki Akahane and Asami Yamazaki for their technical assistance and Trevor Ralph for his editorial assistance.

\section{CONFLICTS OF INTEREST}

The authors do not have any conflicts of interests.

\section{FUNDING}

This study was supported in a part by a research grant from the Japan Society for the Promotion of Science KAKENHI (26460996).

\section{REFERENCES}

1. Kiyosawa K, Sodeyama T, Tanaka E, Gibo Y, Yoshizawa K, Nakano Y, Furuta S, Akahane Y, Nishioka K, Purcell $\mathrm{RH}$, Alter HJ. Interrelationship of blood transfusion, nonA, non-B hepatitis and hepatocellular carcinoma: Analysis by detection of antibody to hepatitis $\mathrm{C}$ virus. Hepatology. $1990 ; 12: 671-5$.
2. Umemura T, Ichijo T, Yoshizawa K, Tanaka E, Kiyosawa $\mathrm{K}$. Epidemiology of hepatocellular carcinoma in Japan. J Gastroenterol. 2009; 44:102-7. https://doi.org/10.1007/ s00535-008-2251-0.

3. Takeda H, Takai A, Inuzuka T, Marusawa H. Genetic basis of hepatitis virus-associated hepatocellular carcinoma: Linkage between infection, inflammation, and tumorigenesis. J Gastroenterol. 2017; 52:26-38. https://doi. org/10.1007/s00535-016-1273-2.

4. Vivier E, Tomasello E, Baratin M, Walzer T, Ugolini S. Functions of natural killer cells. Nat Immunol. 2008; 9:50310. https://doi.org/10.1038/ni1582.

5. Martinet L, Smyth MJ. Balancing natural killer cell activation through paired receptors. Nat Rev Immunol. 2015; 15:243-54. https://doi.org/10.1038/nri3799.

6. Lanier LL. Up on the tightrope: Natural killer cell activation and inhibition. Nat Immunol. 2008; 9:495-502. https://doi. org/10.1038/ni1581.

7. Trowsdale J. Genetic and functional relationships between MHC and NK receptor genes. Immunity. 2001; 15:363-74.

8. Parham P. MHC class I molecules and KIRs in human history, health and survival. Nat Rev Immunol. 2005; 5:20114. https://doi.org/10.1038/nri1570.

9. Bahram S, Inoko H, Shiina T, Radosavljevic M. MIC and other NKG2D ligands: From none to too many. Curr Opin Immunol. 2005; 17:505-9. https://doi.org/10.1016/j. coi.2005.07.016.

10. Colonna M, Borsellino G, Falco M, Ferrara GB, Strominger JL. HLA-C is the inhibitory ligand that determines dominant resistance to lysis by NK1- and NK2-specific natural killer cells. Proc Natl Acad Sci U S A. 1993; 90:12000-4.

11. Barber LD, Percival L, Valiante NM, Chen L, Lee C, Gumperz JE, Phillips JH, Lanier LL, Bigge JC, Parekh RB, Parham P. The inter-locus recombinant HLA-B*4601 has high selectivity in peptide binding and functions characteristic of HLA-C. J Exp Med. 1996; 184:735-40.

12. Cella M, Longo A, Ferrara GB, Strominger JL, Colonna M. NK3-specific natural killer cells are selectively inhibited by Bw4-positive HLA alleles with isoleucine 80. J Exp Med. 1994; 180:1235-42.

13. Tatsumi T, Takehara T. Impact of natural killer cells on chronic hepatitis $\mathrm{C}$ and hepatocellular carcinoma. Hepatol Res. 2016; 46:416-22. https://doi.org/10.1111/hepr.12619.

14. Kawarabayashi N, Seki S, Hatsuse K, Ohkawa T, Koike Y, Aihara T, Habu Y, Nakagawa R, Ami K, Hiraide H, Mochizuki H. Decrease of CD56(+)T cells and natural killer cells in cirrhotic livers with hepatitis $\mathrm{C}$ may be involved in their susceptibility to hepatocellular carcinoma. Hepatology. 2000; 32:962-9. https://doi. org/10.1053/jhep.2000.19362.

15. Khakoo SI, Thio CL, Martin MP, Brooks CR, Gao X, Astemborski J, Cheng J, Goedert JJ, Vlahov D, Hilgartner M, Cox S, Little AM, Alexander GJ, et al. HLA and NK cell inhibitory receptor genes in resolving hepatitis $\mathrm{C}$ 
virus infection. Science. 2004; 305:872-4. https://doi. org/10.1126/science.1097670.

16. Suppiah V, Gaudieri S, Armstrong NJ, O'Connor KS, Berg T, Weltman M, Abate ML, Spengler U, Bassendine M, Dore GJ, Irving WL, Powell E, Hellard M, et al. IL28B, HLA-C, and KIR variants additively predict response to therapy in chronic hepatitis $\mathrm{C}$ virus infection in a European Cohort: A cross-sectional study. PLoS Med. 2011; 8:e1001092. https:// doi.org/10.1371/journal.pmed.1001092.

17. Vidal-Castineira JR, Lopez-Vazquez A, Diaz-Pena R, Alonso-Arias R, Martinez-Borra J, Perez R, FernandezSuarez J, Melon S, Prieto J, Rodrigo L, Lopez-Larrea C. Effect of killer immunoglobulin-like receptors in the response to combined treatment in patients with chronic hepatitis C virus infection. J Virol. 2010; 84:475-81. https:// doi.org/JVI.01285-09 [pii] 10.1128/JVI.01285-09.

18. Nozawa Y, Umemura T, Joshita S, Katsuyama Y, Shibata S, Kimura T, Morita S, Komatsu M, Matsumoto A, Tanaka E, Ota M. KIR, HLA, and IL28B variant predict response to antiviral therapy in genotype 1 chronic hepatitis $\mathrm{C}$ patients in Japan. PLoS One. 2013; 8:e83381. https://doi. org/10.1371/journal.pone.0083381.

19. Fitzmaurice K, Hurst J, Dring M, Rauch A, McLaren PJ, Günthard HF, Gardiner C, Klenerman P; Irish HCV Research Consortium; Swiss HIV Cohort Study. Additive effects of HLA alleles and innate immune genes determine viral outcome in HCV infection. Gut. 2015; 64:813-9. https://doi.org/10.1136/gutjnl-2013-306287.

20. Lopez-Vazquez A, Rodrigo L, Martinez-Borra J, Perez R, Rodriguez M, Fdez-Morera JL, Fuentes D, RodriguezRodero S, Gonzaez S, Lopez-Larrea C. Protective effect of the HLA-Bw4I80 epitope and the killer cell immunoglobulin-like receptor 3DS1 gene against the development of hepatocellular carcinoma in patients with hepatitis C virus infection. J Infect Dis. 2005; 192:162-5. https://doi.org/10.1086/430351.

21. De Re V, Caggiari L, De Zorzi M, Repetto O, Zignego AL, Izzo F, Tornesello ML, Buonaguro FM, Mangia A, Sansonno D, Racanelli V, De Vita S, Pioltelli P, et al. Genetic diversity of the KIR/HLA system and susceptibility to hepatitis $\mathrm{C}$ virus-related diseases. PLoS One. 2015; 10:e0117420. https://doi.org/10.1371/journal.pone.0117420.

22. Kumar V, Kato N, Urabe Y, Takahashi A, Muroyama R, Hosono N, Otsuka M, Tateishi R, Omata M, Nakagawa H, Koike K, Kamatani N, Kubo M, et al. Genome-wide association study identifies a susceptibility locus for HCVinduced hepatocellular carcinoma. Nat Genet. 2011; 43:4558. https://doi.org/10.1038/ng.809.

23. Thimme R, Oldach D, Chang KM, Steiger C, Ray SC, Chisari FV. Determinants of viral clearance and persistence during acute hepatitis C virus infection. J Exp Med. 2001; 194:1395-406.

24. Kuniholm MH, Kovacs A, Gao X, Xue X, Marti D, Thio CL, Peters MG, Terrault NA, Greenblatt RM, Goedert JJ, Cohen MH, Minkoff H, Gange SJ, et al. Specific human leukocyte antigen class I and II alleles associated with hepatitis C virus viremia. Hepatology. 2010; 51:1514-22. https://doi.org/10.1002/hep.23515.

25. Kim S, Sunwoo JB, Yang L, Choi T, Song YJ, French AR, Vlahiotis A, Piccirillo JF, Cella M, Colonna M, Mohanakumar T, Hsu KC, Dupont B, et al. HLA alleles determine differences in human natural killer cell responsiveness and potency. Proc Natl Acad Sci U S A. 2008; 105:3053-8. https://doi.org/10.1073/ pnas.0712229105.

26. Parsons MS, Zipperlen K, Gallant M, Grant M. Killer cell immunoglobulin-like receptor 3DL1 licenses CD16mediated effector functions of natural killer cells. J Leukoc Biol. 2010; 88:905-12. https://doi.org/10.1189/jlb.1009687.

27. Saunders PM, Vivian JP, Baschuk N, Beddoe T, Widjaja J, O'Connor GM, Hitchen C, Pymm P, Andrews DM, Gras $\mathrm{S}$, McVicar DW, Rossjohn J, Brooks AG. The interaction of KIR3DL1 ${ }^{*} 001$ with HLA class I molecules is dependent upon molecular microarchitecture within the Bw4 epitope. J Immunol. 2015; 194:781-9. https://doi.org/10.4049/ jimmunol.1402542.

28. Anfossi N, Andre P, Guia S, Falk CS, Roetynck S, Stewart CA, Breso V, Frassati C, Reviron D, Middleton D, Romagne F, Ugolini S, Vivier E. Human NK cell education by inhibitory receptors for MHC class I. Immunity. 2006; 25:331-42. https://doi.org/10.1016/j.immuni.2006.06.013.

29. Kim S, Poursine-Laurent J, Truscott SM, Lybarger L, Song YJ, Yang L, French AR, Sunwoo JB, Lemieux S, Hansen TH, Yokoyama WM. Licensing of natural killer cells by host major histocompatibility complex class I molecules. Nature. 2005; 436:709-13. https://doi.org/10.1038/ nature 03847.

30. Thons C, Senff T, Hydes TJ, Manser AR, Heinemann FM, Heinold A, Heilmann M, Kim AY, Uhrberg M, Scherbaum N, Lauer GM, Khakoo SI, Timm J. HLA-Bw4 80(T) and multiple HLA-Bw4 copies combined with KIR3DL1 associate with spontaneous clearance of HCV infection in people who inject drugs. J Hepatol. 2017; 67:462-70. https://doi.org/10.1016/j.jhep.2017.03.040.

31. Cai L, Zhang Z, Zhou L, Wang H, Fu J, Zhang S, Shi M, Zhang $\mathrm{H}$, Yang Y, Wu H, Tien P, Wang FS. Functional impairment in circulating and intrahepatic NK cells and relative mechanism in hepatocellular carcinoma patients. Clin Immunol. 2008; 129:428-37. https://doi.org/10.1016/j.clim.2008.08.012.

32. Wu Y, Kuang DM, Pan WD, Wan YL, Lao XM, Wang D, Li XF, Zheng L. Monocyte/macrophage-elicited natural killer cell dysfunction in hepatocellular carcinoma is mediated by CD48/2B4 interactions. Hepatology. 2013; 57:1107-16. https://doi.org/10.1002/hep.26192.

33. Asahina Y, Tsuchiya K, Tamaki N, Hirayama I, Tanaka T, Sato M, Yasui Y, Hosokawa T, Ueda K, Kuzuya T, Nakanishi H, Itakura J, Takahashi Y, et al. Effect of aging on risk for hepatocellular carcinoma in chronic hepatitis $\mathrm{C}$ virus infection. Hepatology. 2010; 52:518-27. https://doi. org/10.1002/hep.23691. 
34. Solana R, Campos C, Pera A, Tarazona R. Shaping of NK cell subsets by aging. Curr Opin Immunol. 2014; 29:56-61. https://doi.org/10.1016/j.coi.2014.04.002.

35. Almeida-Oliveira A, Smith-Carvalho M, Porto LC, Cardoso-Oliveira J, Ribeiro Ados S, Falcao RR, Abdelhay E, Bouzas LF, Thuler LC, Ornellas MH, Diamond HR. Age-related changes in natural killer cell receptors from childhood through old age. Hum Immunol. 2011; 72:31929. https://doi.org/10.1016/j.humimm.2011.01.009.

36. Jinushi M, Takehara T, Tatsumi T, Hiramatsu N, Sakamori $\mathrm{R}$, Yamaguchi S, Hayashi N. Impairment of natural killer cell and dendritic cell functions by the soluble form of MHC class I-related chain A in advanced human hepatocellular carcinomas. J Hepatol. 2005; 43:1013-20. https://doi. org/10.1016/j.jhep.2005.05.026.

37. Jinushi M, Takehara T, Tatsumi T, Kanto T, Groh V, Spies T, Kimura R, Miyagi T, Mochizuki K, Sasaki Y, Hayashi N. Expression and role of MICA and MICB in human hepatocellular carcinomas and their regulation by retinoic acid. Int J Cancer. 2003; 104:354-61. https://doi. org/10.1002/ijc.10966.

38. Coudert JD, Held W. The role of the NKG2D receptor for tumor immunity. Semin Cancer Biol. 2006; 16:333-43. https://doi.org/10.1016/j.semcancer.2006.07.008.
39. Goto K, Kato N. MICA SNPs and the NKG2D system in virus-induced HCC. J Gastroenterol. 2015; 50:261-72. https://doi.org/10.1007/s00535-014-1000-9.

40. Umemura T, Wang RY, Schechterly C, Shih JW, Kiyosawa $\mathrm{K}$, Alter HJ. Quantitative analysis of anti-hepatitis C virus antibody-secreting B cells in patients with chronic hepatitis C. Hepatology. 2006; 43:91-9. https://doi.org/10.1002/ hep.20917.

41. Tajik N, Shahsavar F, Nasiri M, Radjabzadeh MF. Compound KIR-HLA genotype analyses in the Iranian population by a novel PCR-SSP assay. Int J Immunogenet. 2010; 37:159-68. https://doi.org/10.1111/j.1744-313X.2010.00906.x.

42. Vilches C, Castano J, Gomez-Lozano N, Estefania E. Facilitation of KIR genotyping by a PCR-SSP method that amplifies short DNA fragments. Tissue Antigens. 2007; 70:415-22.

43. Steinle A, Li P, Morris DL, Groh V, Lanier LL, Strong RK, Spies T. Interactions of human NKG2D with its ligands MICA, MICB, and homologs of the mouse RAE-1 protein family. Immunogenetics. 2001; 53:279-87. 